is not the reason why it has a special claim on public attention. Nor, for that matter, is its tradition, which is often a spurious justification of irritating anachronism. What matters is the quality of the education offered to undergraduates, the imaginativeness of the training in research offered to graduate students, the range and depth of the university's scholarship and research and its value as an example of how a university should conduct its affairs. The North inquiry appears to have been prompted, nevertheless, mostly by external forces - notably by the continuing pressure on public support for British universities, with rules of thumb linking public subventions separately to student numbers and research attainment.

Oxford has a structural problem of its own choosing, the balance of power between the colleges at which students compete for places and to which they then nominally belong and the university which, in due course, awards the same students their degrees. At Oxford, the colleges collectively are relatively more powerful (because many of them are richer) than at the University of Cambridge, where in principle the same system obtains. It is not irrelevant that both systems have their roots in the mediaeval university, in which the university provided only public examinations while the colleges were dormitories at which students lived while being taught privately by tutors to whom they paid fees. That explains why at both universities (but with special insistence at Oxford), the provision of tutorial instruction by established academics is held to be a distinctive part of undergraduate education.

The tutorial system is indeed a valuable institution, but its value diminishes as the years go by, especially in science, where laboratory work and time spent in the computer room are ever more important. That does not imply that Oxford should be willing to abandon its tutorial system for the benefit of the university, but simply that its colleges should recognize the limitations of the system (not least, that while all tutors are supposed equal, some are more equal than others). There is a case for a decisive shift of responsibility for undergraduate education towards the central university. At a time when accountability is all the rage, students' accountability towards their teachers (by means of more regular examinations) would also serve a useful purpose.

But Oxford's most urgent need is to strengthen its research, which is patchy compared with that at Cambridge. To be sure, the two universities differ very little in the ratings their academic departments were awarded in last year's attempt at the assessment of research quality, but that is a misleading index. The Oxford problem, in any case, is not the absence of excellence, but the scope and depth of its collective research in science. The difficulty, in present circumstances, is that intensifying efforts across the board would require extra people (which would be expensive) and even bricks and mortar (which are even harder to come by now). At the very least, one outcome of the North inquiry should be a more effective mechanism for uniting the colleges and the university as a whole behind a coordinated strategy for research.

\section{Moon-landing blues}

The 25 years since the first landing on the Moon have been a predictable disappointment for space flight.

THE celebrations last weekend of the anniversary of the departure of the Apollo XII spacecraft for the Moon could not have been timed better for those in the US Congress whose ambition is to see space-station Freedom well-funded and eventually launched into an orbit about the Earth. If the US National Aeronautics and Space Administration(NASA) had been hoping that the anniversary would rekindle taxpayers' enthusiasm for such adventures, it has probably not been disappointed. But suspicions that NASA arranged the impact of Shoemaker-Levy on Jupiter to enhance the general excitement are without foundation.

This anniversary (that of the 'walk' by Neil Armstrong and 'Buzz' Aldrin fell yesterday) shows how little has changed in a quarter of a century. In 1969, it seemed proper to praise both visitors to the Moon for their composure under trying circumstances (not the least of which must have been the international television audience of 600 million), to commend NASA for its management of the project, to remark that little would be discovered about the Moon that had not already been found out, to suggest that strictly scientific exploration of the rest of the Solar System would be better carried out by instrumented spacecraft, to call for a better way of deciding what space flight is for and to acknowledge that, nevertheless, the visit to the Moon fired the general imagination (see Nature 223, 333; 1969).

That opinion was over-confident of NASA's management, much clouded in recent years, and over-dismissive of the benefits that would accrue from the analysis of Moon rocks, which established that there were two distinct epochs of surface cratering early in the Moon's history, at about 4 billion years ago. The intellectual consequences of the landing on the Moon were also a surprise; people were more often persuaded by Apollo's startling images of the fragility of the Earth than that the next stopping-place must be Mars or somewhere like it.

The purpose of the Apollo venture was never simple. Decided on by President John F. Kennedy in the wake of the Sputnik humiliation, it was mostly a move in the Cold War. It restored the reputation of the United States for technological prowess, and it lifted American spirits to a greater degree than would have the distribution of the total cost (roughly $\$ 20$ billion) among the then-population (which would have given each \$100). But the purpose of space flight from the United States (or anywhere) is still undefined except in the language of the travel brochure, while the technological developments that might have made distant journeys feasible have not come about, largely through neglect. Meanwhile, in the United States, the space station project limps on from year to year (see page 167), exciting little enthusiasm or imagination. Would it not be better to concentrate instead of the exploration of the Solar System by the means already shown to be effective? 